\title{
Clinical significance of sCD163 and its possible role in asthma (Review)
}

\author{
YUE ZHI ${ }^{1,2}$, PENG GAO $^{1}$, XIUQIN XIN $^{1}$, WEI LI $^{1}$, LEI JI $^{2}$, LIN ZHANG $^{1}$, XUEYANG ZHANG $^{1}$ and JIE ZHANG ${ }^{1}$ \\ ${ }^{1}$ Department of Respiratory and Critical Care Medicine, The Second Affiliated Hospital of Jilin University; \\ ${ }^{2}$ Department of Respiration, Changchun Center Hospital, Changchun, Jilin 130022, P.R. China
}

Received February 1, 2016; Accepted January 26, 2017

DOI: $10.3892 / \mathrm{mmr} .2017 .6393$

\begin{abstract}
Macrophages exert important functions in the balance and efficiency of immune responses, and participate in innate and adaptive immunity. The proinflammatory actions of macrophages are implicated in autoimmune diseases. Unlike classically activated M1 macrophages, the alternatively activated cluster of differentiation (CD) $163^{+}$ and $\mathrm{CD}_{206^{+}} \mathrm{M} 2$ macrophages are involved in tissue repair and wound healing, and use oxidative metabolism to support their long-term functions. CD163 is a member of the scavenger receptor superfamily, categorized into class $\mathrm{B}$, and its soluble(s) form, sCD163, is a marker of activated M2 macrophages. CD163 is selectively expressed in cells of the monocyte and macrophage lineages; however, its biological role has yet to be elucidated. The expression of sCD163 is markedly induced by anti-inflammatory mediators, such as glucocorticoids and interleukin-10, whereas it is inhibited by proinflammatory mediators, such as interferon- $\gamma$. These findings suggest that CD163 may serve as a potential target for the therapeutic modulation of inflammatory responses. The concentration of sCD163 in blood is associated with acute and chronic inflammatory processes in autoimmune disorders of connective tissue, fat metabolism and cardiovascular diseases, and it can be used for the assessment of cancer prognosis. A role for sCD163 in the pathogenesis of asthma has also been proposed. The present review serves to present the available knowledge concerning the implication of sCD163 in the pathophysiological mechanisms of asthma, and evaluate its potential as a biomarker and possible therapeutic target for asthma.
\end{abstract}

Correspondence to: Professor Jie Zhang, Department of Respiratory and Critical Care Medicine, The Second Affiliated Hospital of Jilin University, 218 Ziqiang Street, Changchun, Jilin 130022, P.R. China

E-mail: doctorzhangj@sina.com

Key words: macrophages, sCD163, asthma, proinflammatory mediators

\section{Contents}

1. Introduction

2. Characteristics of M2 macrophages

3. CD163 structure

4. sCD163 expression

5. Clinical significance of sCD163 expression

6. CD163-deficient animal model

7. Functions of macrophages and potential role of CD163 in asthma

8. Conclusion

\section{Introduction}

Macrophages are involved in several pathological conditions, including severe sepsis, autoimmune disorders, cancer and low-grade inflammatory disorders, such as metabolic syndrome, atherosclerosis and asthma. Macrophages are essential in regulating the activation and resolution of immune responses, and can influence the progression of a disease (1). Cluster of differentiation (CD)163 is a monocyte/macrophage-associated antigen that has been identified as a hemoglobin $(\mathrm{Hb})$ scavenger receptor with anti-inflammatory and immunoregulatory properties. This surface receptor undergoes ectodomain shedding, triggered by an inflammatory stimulus, generating the soluble(s) form, $\mathrm{sCD} 163$, in plasma (2). CD163 is a scavenger receptor for the endocytosis of $\mathrm{Hb}$ and haptoglobin ( $\mathrm{Hp})-\mathrm{Hb}$ complexes (3). It is almost exclusively expressed on monocytes and macrophages, and participates in the modulation of inflammatory responses $(3,4)$. sCD163 is a novel marker associated with states of low-grade inflammation characteristic of conditions such as diabetes, obesity, liver disease and atherosclerosis (5).

The proteolytic cleavage of monocyte-bound CD163 by matrix metalloproteinases (MMPs), which is triggered by exposure to oxidative stress or an inflammatory stimulus, releases sCD163 (6-8). Oxidative stress pathways, induced by prostaglandin F2 $\alpha$ (PGF2 $\alpha$ ) and 8-iso-PGF2 $\alpha$, enhance the expression of tumor necrosis factor (TNF)- $\alpha$ and CD163 (8). Lipopolysaccharide (LPS) can also increase the levels of sCD163 and TNF- $\alpha$, via stimulation of a disintegrin and metalloproteinase metallopeptidase domain 17 (ADAM17), which is known to mediate the shedding of the extracellular domains of CD163 and TNF- $\alpha$ (9). The significant negative correlation, 
which was revealed between membrane CD163 expression and sCD163 levels, suggests that plasma sCD163 may be derived from circulating monocytes, in addition to being secreted by tissue macrophages (10). sCD163 is constitutively being shed from the cell surface into the circulation, and it is stable and easily detectable in serum. The present review focuses on examining the role of sCD163 in various inflammatory disorders, including inflammatory disorders of the airways, and specifically in the pathogenesis of asthma.

\section{Characteristics of M2 macrophages}

Classically activated M1 macrophages are the first line of defense against bacterial infections and obtain energy through glycolysis. Cell-surface markers of classically activated macrophages are not well defined; however, CD40 is predominantly used $(11,12)$. Conversely, alternatively activated M2 macrophages, which are $\mathrm{CD}_{163}{ }^{+}$and $\mathrm{CD} 206^{+}$, are involved in tissue repair and wound healing, and use oxidative metabolism to fuel their long-term functions. Granulocyte-macrophage colony-stimulating factor (GM-CSF) and interferons (IFNs) can enhance the macrophage lineage, and modulate macrophage differentiation and function. M1 macrophages can be produced in vitro by culture and subsequent differentiation of human peripheral blood monocytes. The cytokines M-CSF, interleukin (IL)-4 and IL-10 stimulate monocyte differentiation into M2 macrophages (13). M1 macrophages secrete proinflammatory cytokines, such as IL-12 and TNF- $\alpha$, and also have antigen-presenting capacity and promote Th1 immune responses.

Conversely, M2 macrophages secrete anti-inflammatory mediators, such as IL-10, and have poor antigen-presenting capabilities and stimulate the generation of regulatory $\mathrm{T}$ cells (13-15). The activation of M2 macrophages is primarily triggered by Thelper (Th) 2 cytokines, such as IL-4, IL-13 and IL-10, as well as anti-inflammatory mediators, such as glucocorticoids (16). CD163 ${ }^{+} \mathrm{M} 2$ macrophages reduce M1 populations through the release of anti-inflammatory cytokines, such as IL-10. Macrophage mannose receptor (MRC)-1, IL-13, IL-1 receptor antagonist (IL-1RA) and CD163 serve important roles in M2 differentiation (17). Monocyte-derived macrophages, classically activated via IFN- $\gamma$ priming and LPS stimulation, demonstrate a decreased CD163 expression; however, the alternative activation route, involving IL-4/IL-13 priming, does not affect the expression of CD163 and calprotectin on macrophages (18). The presence of IFN- $\gamma$, indicative of Th1 inflammation, or a prolonged exposure to IL-4, promotes apoptosis of macrophages and suppresses M2 differentiation, which leads to a reduction in the clearance of apoptotic neutrophils, increased accumulation of apoptotic cells and persistent inflammation (19). Conversely, in the presence of IL-17, indicative of a Th17 response, macrophage apoptosis is prevented and M2 differentiation is stimulated, which ensures that apoptotic neutrophils are cleared efficiently and anti-inflammatory conditions are restored (Fig. 1) (19). Following IL-4 or IL-13 stimulation, M2 macrophages derived from peripheral blood mononuclear cells exhibit markedly increased mRNA expression levels of thymus activation regulating chemokine (CCL) 11, CCL17, CCL24 and CCL26, and the production of CCL17 and CCL24 is also potentiated (20).

\section{CD163 structure}

CD163 is a $130-\mathrm{kDa}$, type I transmembrane protein, which belongs to class $\mathrm{B}$ of the cysteine-rich scavenger receptor family, and was first identified in 1987 (21). The expression of CD163 on circulating monocytes and most tissue macrophages is constitutive and/or induced by some stimuli (22). CD163 has been reported to bind human pathogenic bacteria $(10,23)$ and TNF- $\alpha$-like weak inducer of apoptosis (TWEAK) (24). Using western blot analysis of CD163 variants, a panel of 10 monoclonal antibodies was mapped to scavenger receptor cysteine-rich (SRCR) domains 1, 3, 4, 6, 7 and 9 (25). Four of the SRCR domains of CD163 (domains 2, 3, 7 and 9) have conserved consensus motifs for $\mathrm{Ca}^{2+}$ binding, whereas domain 5 has a potentially/semi-conserved $\mathrm{Ca}^{2+}$ binding site. The other four SRCR domains have at least one non-conservative mutation of an essential residue in the consensus $\mathrm{Ca}^{2+}$ binding sequences (26).

Only the two antibodies targeting SRCR domain 3 can effectively inhibit ligand binding. This is an exposed domain and a critical factor regulating the $\mathrm{Ca}^{2+}$-sensitive coupling of $\mathrm{Hp}-\mathrm{Hb}$ complexes (25). Since CD163 is a scavenger receptor on the surface of macrophages, its extracellular region, consisting of nine SRCR domains, can be stimulated by inflammation or other stimuli, resulting in the release of its soluble form, sCD163, in the plasma $(22,25)$. Ligands of Toll-like receptors (TLR) 2, 4 and 5 can stimulate ectodomain shedding of CD163, thereby releasing sCD163 (3). CD163 and pro-TNF- $\alpha$ are transmembrane proteins subjected to hydrolytic cleavage by the inflammation-responsive proteases ADAM17 $(23,27)$ and ADAM10 (23) from the monocyte surface. This results in the release of sCD163 and bioactive TNF- $\alpha$ in the circulation. A sequence comparison of their juxtamembrane region identified similar palindromic sequences in human CD163 (1044Arg-Ser-Ser-Arg) and pro-TNF- $\alpha$ (78Arg-Ser-Ser-Ser-Arg) (Fig. 2) (27).

sCD163 and immunoglobulin $\mathrm{G}$ interact with the free $\mathrm{Hb}$ in plasma, leading to the endocytosis of the sCD163-Hb-IgG complex via the $\mathrm{Fc} \gamma$ receptor $(\mathrm{Fc} \gamma \mathrm{R})$ into monocytes. The endocytosed sCD163 is recycled to restore the homeostasis of CD163 on the monocyte membrane, whereas the internalized $\mathrm{Hb}$ is catabolized (28). Paracrine transactivation of endothelial cells is mediated by the shed sCD163, which detoxifies and clears residual $\mathrm{Hb}$. Circulating sCD163 only weakly competes with membrane CD163 for the uptake of $\mathrm{Hp}-\mathrm{Hb}$ complexes, and $\mathrm{Hp}-\mathrm{Hb}$ saturation of sCD163 in serum can only be achieved with a large surplus of $\mathrm{Hp}-\mathrm{Hb}$ complex. These findings indicated that the $\mathrm{Hp}-\mathrm{Hb}$ complex may be harder to dissociate from the membrane form of CD163 (Fig. 3) (29).

\section{SCD163 expression}

CD163 is expressed only on cells of the monocytic-macrophage lineage, and its expression increases as monocytes mature into macrophages. CD163 expression is particularly high on macrophages in the liver (Kupffer cells), red pulp of the spleen, lungs and bone marrow (21). sCD163 is a marker of activated macrophages (30). Following an inflammatory stimulus or oxidative stress, sCD163 is released from the cell surface by proteolytic cleavage of monocyte-bound CD163 through 


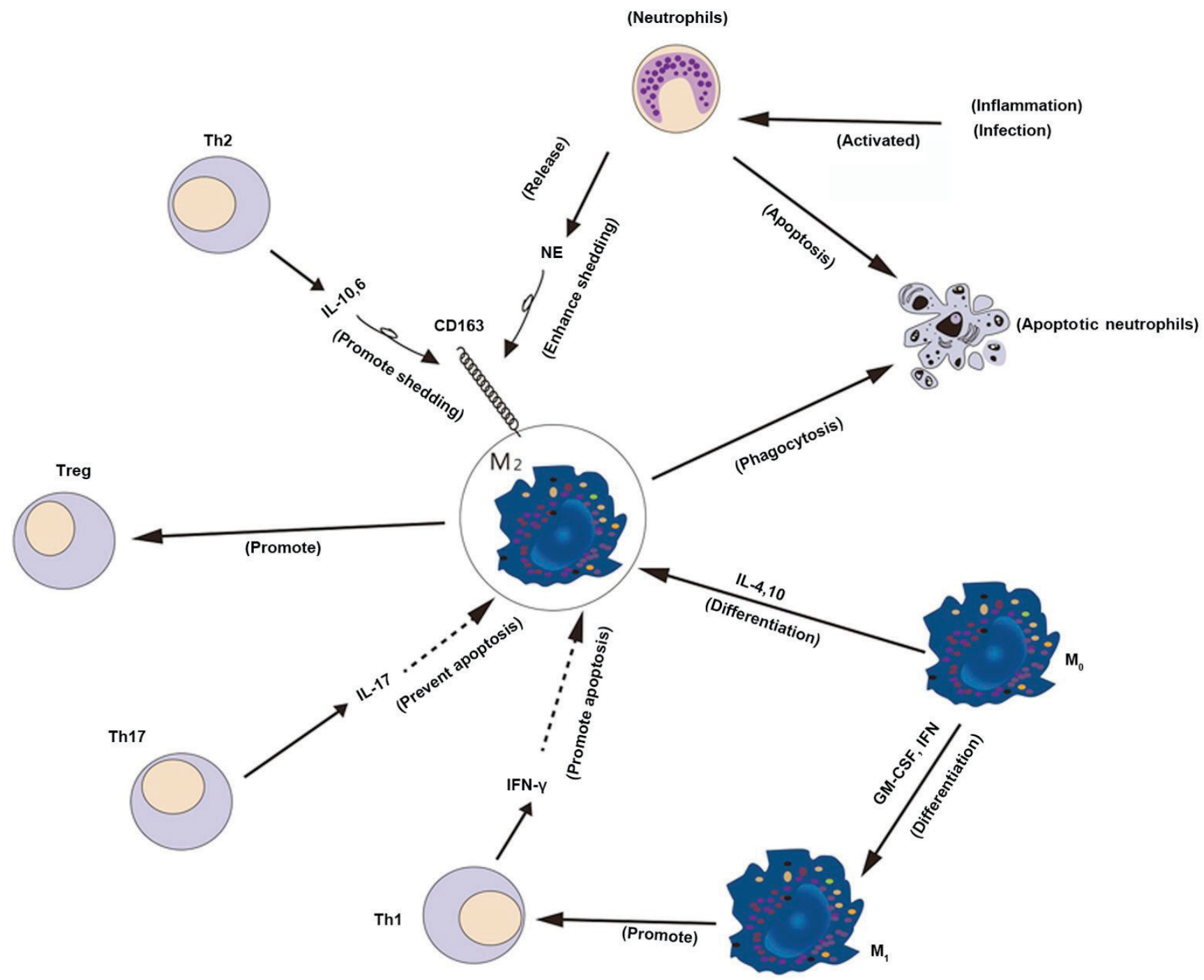

Figure 1. Macrophages serve a key role in regulating the activation and resolution of immune responses. The induction of M0 macrophages by inflammatory mediators, such as IL-4 and IL-10, results in the differentiation of M2 macrophages. IL-17 (in a Th17 environment) prevents macrophage apoptosis, whereas IFN- $\gamma$ (during Th1 inflammation) promotes apoptosis of macrophages. NE stimulates CD163 shedding, a marker of M2 macrophage activation. Macrophages effectively eliminate apoptotic neutrophils via phagocytosis. IL, interleukin; Th, T helper; IFN, interferon; NE, neutrophil elastase; CD, cluster of differentiation; Treg, T regulatory.

the action of MMPs (6-8) and after LPS stimulation $(22,31)$, whereas proinflammatory cytokines, such as TNF, reduce CD163 expression (3). Furthermore, TLR7 levels have been associated with concentrations of IL-10, IL-1RA and CD163 (32).

The expression of CD163 is induced by corticosteroids (3,33-35), IL-10 (3,22,33-35), IL-6 (12,34,36), IL-12 (37), the chemokine (C-X-C motif) ligand (CXCL)-10(37), and oxidative stress (8). sCD163 protects monocytes from hyperactivation during bacterial infections by dampening the secretion of the proinflammatory cytokines TNF- $\alpha$, IL-1 $\beta$, IL- 6 and IL-8 (38). The actions of sCD163 and TNF- $\alpha$ seem to be interconnected, and the sCD163/TNF- $\alpha$ ratio is higher in patients with uncomplicated malaria (39). In vitro, stimulation of murine monocyte-macrophage cells resulted in increased TNF- $\alpha$ release accompanied by elevated CD163 expression (17). In patients with cirrhosis and hepatitis $\mathrm{C}$ infection, sCD163 also appears significantly correlated with TNF- $\alpha(40)$.

\section{Clinical significance of SCD163 expression}

Elevated sCD163 serum levels are currently the most specific marker for distinguishing bacterial infections, such as brucellosis, or those caused by Staphylococcus aureus and Haemophilus influenzae $(41,42)$, from non-bacterial infections, based on previously described results comparing lumbar puncture with composite reference standards (43). sCD163 expression is correlated with levels of IL-6 $(21,41)$, IL-10 and IL-8 (44), but not with LPS-binding protein, procalcitonin (PCT) or C-reactive protein (CRP) levels (41). Plasma levels of CRP, PCT and SCD163 are increased in patients with bacterial infections (45). CRP and PCT are also valuable diagnostic tools and can be used as markers of bacterial infections. In patients with sepsis, sCD163 levels were significantly lower than in patients with severe sepsis; however, sCD163 levels in both groups were considerably increased compared with in the control group $(46,47)$. Furthermore, higher sCD163 levels were reported in patients with sepsis who succumbed compared 


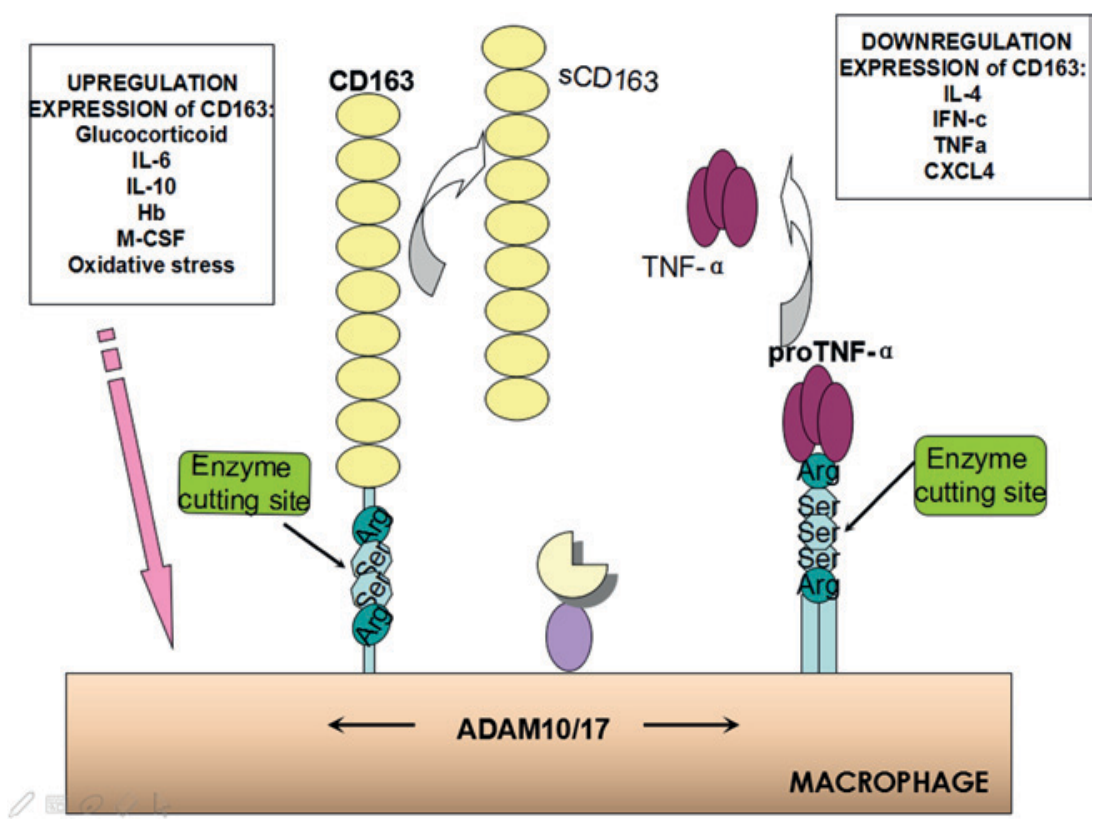

Figure 2. Shedding of sCD163. Several inflammatory signals have been demonstrated to induce ectodomain shedding of sCD163 in vitro. ADAM17/10 mediates shedding of CD163 and TNF- $\alpha$ upon stimulation by inflammatory stimuli. CD163 and pro-TNF- $\alpha$ are rapidly cleaved from the surface of activated macrophages by an ADAM17/10-mediated mechanism. The half-life of sCD163 is much longer than that of TNF- $\alpha$. Similar palindromic sequences in human CD163 (1044Arg-Ser-Ser-Arg) and pro-TNF- $\alpha$ (78Arg-Ser-Ser-Ser-Arg) were identified by a comparison of the sequences of the juxtamembrane region of the proteins. s, soluble; CD, cluster of differentiation; ADAM, a disintegrin and metalloproteinase; TNF, tumor necrosis factor; IL, interleukin; Hb, hemoglobin; M-CSF, macrophage-colony stimulating factor; IFN, interferon; LPS, lipopolysaccharide; CXCL, (C-X-C motif) ligand.

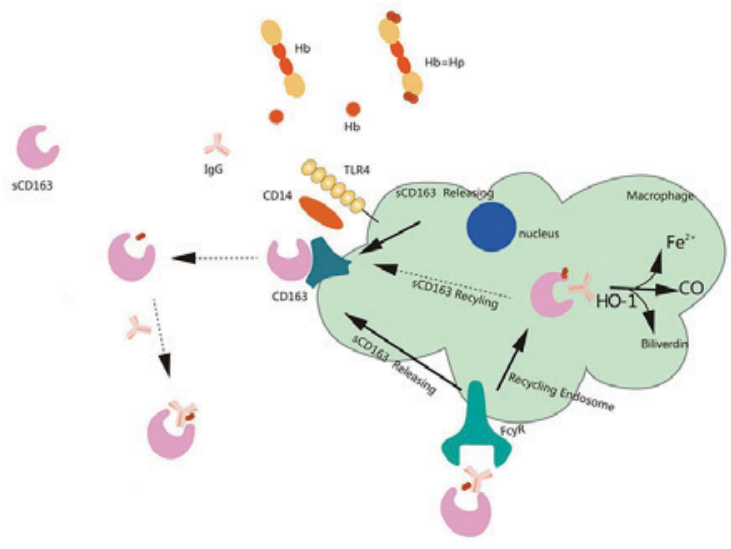

Figure 3. A hypothetical model of Hp-independent intravascular detoxification and clearance of cell-free $\mathrm{Hb}$ by CD163. Hb induces shedding of CD163 into the plasma and the produced sCD163 captures and quenches the residua redox-reactive $\mathrm{Hb}$. Subsequently, $\mathrm{IgG}$ interacts with the sCD163-Hb complex. The sCD163-Hb-IgG complex then elicits an autocrine loop of endocytosis via $\mathrm{Fc} \gamma \mathrm{R}$ on monocytes and subsequent recycling of the internalized sCD163 via endosomes to restore CD163 homeostasis in the membrane, whereas the internalized $\mathrm{Hb}$ is catabolized by $\mathrm{HO}-1$. Hp, haptoglobin; $\mathrm{Hb}$, hemoglobin; $\mathrm{CD}$, cluster of differentiation; s, soluble; Ig, immunoglobulin; Fc $\gamma \mathrm{R}, \mathrm{Fc} \gamma$ receptor; HO, heme oxygenase; TLR, Toll-like receptor.

with in surviving patients (46-48). MRC and sCD163 expression is markedly increased in septic patients compared with in non-septic patients and healthy controls (48). Increases in serum sCD163 levels were delayed in animals that were infected with virulent strains of Haemophilus parasuis (44).

sCD163 serum levels are elevated in patients with acute and chronic liver diseases. In patients with cirrhosis, sCD163 concentration is $\sim 3$ times higher compared with in healthy controls $(49,50)$. In addition, although sCD163 is linearly associated with the pressure gradient in the portal vein, its concentration remained unaltered after a transjugular intrahepatic portosystemic shunt procedure (51). High sCD163 serum levels are considered an independent risk factor for variceal/gastrointestinal bleeding, portal hypertension and mortality in patients with cirrhosis $(49,52,53)$. High serum sCD163 concentrations have been reported during acute liver damage, but are lower in acute hepatitis; however, in both conditions, they are higher than those reported in patients with chronic hepatitis $(12,26,30)$. Hepatitis B infection is characterized by higher serum sCD163 levels when compared with hepatitis C, particularly when accompanied by liver fibrosis $(40,54)$, whereas higher serum SCD163 concentrations have been associated with higher mortality $(55,56)$.

sCD163 is also associated with obesity, insulin resistance, and the development of type 2 diabetes (57-59). In patients with type 2 diabetes, sCD163 appears strongly associated with known risk factors, such as physical inactivity, body mass index, elevated CRP levels and triglyceride content (60). High serum sCD163 levels have been associated with complications in patients with type 2 and type 1 diabetes mellitus $(59,61)$; conversely, levels of soluble TWEAK, a cytokine that regulates inflammation, angiogenesis and tissue remodeling, follow an opposite trend (61). Serum sCD163 levels are significantly higher in obese patients compared with in lean patients, whereas efferocytosis by M2 macrophages appears to be impaired in obese patients (61-63). A low-fat diet reduced the levels of sCD163 $(64,65)$; however, a 12-week exercise program had no such effect (66).

sCD163 has been associated with arterial inflammation, non-calcified plaque formation, perivascular fat accumulation and carotid atherosclerosis $(67,68)$. Neutrophil elastase has been demonstrated to promote CD163 shedding, and CD163 
Table I. Expression of sCD163 in different diseases and its clinical significance.

\begin{tabular}{|c|c|c|c|}
\hline Disease & sCD163 concentration & Clinical significance & (Refs.) \\
\hline $\begin{array}{l}\text { Acute respiratory distress } \\
\text { syndrome (mean) }\end{array}$ & $>1,020 \mathrm{ng} / \mathrm{ml}$ & $\begin{array}{l}\text { Associated with increased } \\
\text { risk of mortality }\end{array}$ & (2) \\
\hline Cirrhosis (mean $\pm \mathrm{SD}$ ) & $4.7 \pm 2.5 \mathrm{mg} / 1$ & Associated with gastrointestinal & (49) \\
\hline Controls & $1.6 \pm 0.5 \mathrm{mg} / 1$ & bleeding, hepatic venous pressure gradient & \\
\hline Systemic sclerosis & $984 \pm 420 \mathrm{ng} / \mathrm{ml}$ & Associated with greater skin involvement & $(70)$ \\
\hline Controls (mean \pm SD) & $823 \pm 331 \mathrm{ng} / \mathrm{ml}$ & & \\
\hline Early rheumatoid arthritis [median (IQR)] & $1.69(1.42-2.10) \mathrm{mg} / \mathrm{l}$ & Associated with disease activity & $(76)$ \\
\hline Epithelial ovarian cancers & $3,220 \mathrm{ng} / \mathrm{ml}$ & Used in diagnosis; associated with & $(81)$ \\
\hline Controls (mean) & $2,488 \mathrm{ng} / \mathrm{ml}$ & poor prognostic factors & \\
\hline Type 1 diabetes mellitus [median (IQR)] & $285.0(247.7-357.1) \mathrm{ng} / \mathrm{ml}$ & Associated with cardiovascular risk & $(61)$ \\
\hline Controls & $224.8(193.3-296.5) \mathrm{ng} / \mathrm{ml}$ & & \\
\hline Sepsis (mean $\pm \mathrm{SD}$ ) & $105.32 \pm 145.87 \mathrm{mg} / \mathrm{l}$ & Associated with poor prognosis & $(46)$ \\
\hline Severe sepsis & $233.32 \pm 171.78 \mathrm{mg} / \mathrm{l}$ & & \\
\hline Control group & $44.19 \pm 86.48 \mathrm{mg} / 1$ & & \\
\hline $\begin{array}{l}\text { Obese [median (IQR)] } \\
\text { Normal weight controls }\end{array}$ & $974(657-1,272) \mathrm{ng} / \mathrm{ml}$ & $\begin{array}{l}\text { Used as a marker for predicting the } \\
\text { risk of insulin resistance }\end{array}$ & $(58)$ \\
\hline Allergic asthma (serum) (mean $\pm \mathrm{SD})$ & $599(423-892) \mathrm{ng} / \mathrm{ml}$ & & \\
\hline Controls (serum) & $1,030 \pm 499 \mathrm{ng} / \mathrm{ml}$ & Associated with anti-inflammatory & $(33)$ \\
\hline Allergic asthma (sputum) & & effects of inhaled corticosteroid therapy & \\
\hline Controls (sputum) & $\begin{array}{c}930 \pm 334.5 \mathrm{ng} / \mathrm{ml} \\
4.78 \pm 3.34 \mathrm{ng} / \mathrm{ml} \\
1.8 \pm 0.41 \mathrm{ng} / \mathrm{ml}\end{array}$ & & \\
\hline
\end{tabular}

IQR, interquartile range; SD, standard deviation.

expression on the surfaces of macrophages was decreased, resulting in impaired of $\mathrm{Hb}$ clearance by macrophages. These effects may be correlated with acute coronary syndrome and stable angina pectoris, and may increase the risk of myocardial infarction (69). It has been demonstrated that CD163 can bind and neutralize TWEAK (70), whereas SCD163 functions as a decoy receptor for TWEAK. An imbalance between TWEAK and CD163 could reflect the progression of atherosclerosis. Furthermore, the CD163/TWEAK plasma ratio may have potential as a biomarker of atherosclerosis in asymptomatic individuals (71). Substantially elevated sCD163/sTWEAK ratios have been reported in patients with critical limb ischemia and peripheral artery disease (72,73).

Serum sCD163 levels were estimated in patients with systemic sclerosis ( $\mathrm{SSc}$ ) as an indicator of disease deterioration, pulmonary fibrosis and pulmonary hypertension (4,6,74,75). sCD163 levels and the sCD163/sTWEAK ratio were significantly increased in patients with SSc compared with in controls. Elevated plasma sCD163 and an increased sCD163/sTWEAK ratio were associated with a lower risk of digital ulcers in patients with SSc (70).

Early rheumatoid arthritis (RA) patients have significantly increased sCD163 plasma levels, which are reduced following treatment. Therefore it may be hypothesized that sCD163 is implicated in RA activity, although an association between SCD163 and disease activity has yet to be demonstrated (37,76). sCD163 shed from resident tissue macrophages were abundant in inflamed synovium (77). In addition,
sCD163 levels have been correlated with the Systemic Lupus Erythematosus Disease Activity Index (78). Patients with elevated serum sCD163 levels exhibit significantly higher rates of anti-double-strand-DNA antibodies (79).

Macrophages serve key roles in tumor development and invasion in several types of human cancer, and sCD163 is a marker of alternatively activated M2 macrophages. High sCD163 concentrations have been detected in hepatocellular carcinoma (80), ovarian cancer $(81,82)$, T cell lymphoma (83) and multiple myeloma (84). Furthermore, elevated sCD163 concentrations are associated with a poor prognosis in patients with cancer $(40,81-83)$.

In conclusion, sCD163 levels in infection, liver disease, autoimmune disorders, metabolic disease and cancer are elevated, whereas the clinical significance of this elevation varies among the various diseases (Table I).

\section{CD163-deficient animal model}

House dust mite (HDM)-challenged $\mathrm{Cd}_{163^{-/}}$mice have been reported to exhibit increased concentrations of airway eosinophils and develop mucous cell metaplasia (85). In addition, $\mathrm{Cd}_{163} 3^{-/}$mice may demonstrate transiently elevated TWEAK levels, which can stimulate muscle satellite cell proliferation and tissue regeneration in ischemic and non-ischemic limbs. These results suggested a role for sCD163 in muscle regeneration following ischemic injury (86). In CD163-deficient mice, the overall clearance of $\mathrm{Hb}$ has been demonstrated 
to be slightly impaired and follow a one-phase decaying trend (87).

\section{Functions of macrophages and potential role of CD163 in asthma}

Macrophages have a central role in the regulation and efficiency of the immune response, and participate in innate and adaptive immunity. Macrophages exert important functions in autoimmune disorders, including RA, Crohn's disease, psoriasis, sarcoidosis and atherosclerosis. M2 macrophages are associated with responses to anti-inflammatory stimuli and tissue remodeling (88). Since they participate in tissue repair and in the restoration of lung microenvironment homeostasis, M2 macrophages may serve a major role in asthma (89). Macrophages represent the majority of immune cells present in lungs under physiological conditions and serve to dictate the innate defense mechanisms of the airways. Pulmonary macrophage populations are heterogeneous and demonstrate notable plasticity, due to variations in their origin, tissue residency and environmental influences (90). In mice with moderately severe asthma, the population of M1 macrophages is elevated and negatively correlated with the population of M2 $\left(\mathrm{CD}_{163^{+}}\right)$macrophages. Decreased numbers of M2-like macrophages are reported after HDM exposure, and they are negatively correlated with the number of M1 macrophages (88). In addition, macrophages have been implicated in the pathogenesis of chronic obstructive pulmonary disease (COPD). Ex-smokers with COPD have a higher percentage of CD163+ macrophages in bronchoalveolar lavage (BAL) than current smokers. Furthermore, the percentage of CD163 ${ }^{+} \mathrm{M} 2$ macrophages is higher in BAL than in sputum (91). In ovalbumin (OVA)-sensitized mice, exposure to the airborne particulate matter PM2.5 caused a slight increase in the number of neutrophils and macrophages (92). The balance between macrophage phenotypes fluctuates, depending on the severity of allergic airway inflammation (88). This balance is regulated by cytokines, such as IL-13, which is a typical pro-M2-Th2 cytokine that has been linked to allergic diseases and asthma. MicroRNA (miR)-155 may also be involved in regulation of the M1/M2 balance via modulating the effects of IL-13. miR-155 directly targets the IL-13RA1 gene and reduces the protein levels of IL-13RA1, thus preventing the activation of the signal transducer and activator of transcription (STAT) 6 (93).

Serum amyloid P (SAP) inhibits the generation of M2 markers, such as arginase and the chitinase Ym-1, through an Fc $\gamma$ R-dependent mechanism in cultured macrophages. This effect has been correlated with a decrease in STAT6 phosphorylation in SAP-treated M2 macrophages (94). Type 2 cytokines, i.e. IL-4 and IL-13, can drive the differentiation of macrophages into M2 macrophages. This population of macrophages is associated with allergic inflammation (95). Monocytes co-cultured with regulatory $\mathrm{T}$ cells display typical features of alternatively activated macrophages, including upregulated expression of CD206 (macrophage mannose receptor) and CD163, and increased production of CCL18 (96). OVA-sensitized and challenged mice exhibit a significant increase in white blood cells, eosinophilia, mucus accumulation and goblet cell hyperplasia, which were correlated with increased expression of genes associated with alternatively activated M2 macrophages, such as arginase 1,
Ym-1, Ym-2, resistin like- $\alpha$, and eosinophil-associated, ribonuclease A family member 11 . The expression of other genes associated with asthma, including Fc $\gamma$ RIIb, MMP-14, CCL-8, CCL-17 (20,97), ADAM-8, lymphotoxin $\beta$ receptor 1 (LT $\beta R 1)$, aquaporin-9 and IL-7R, is also upregulated in bronchoalveolar macrophages isolated from OVA-sensitized/challenged mice compared with in macrophages from healthy controls (97).

CD163 participates in inflammatory responses and may contribute to connective tissue remodeling. CD163 may function as a pulmonary defense element, as suggested by its local expression in the lungs, and its secretion during lung infection and as part of inflammatory respiratory responses (98). Cell surface expression of CD163 on alveolar macrophages is reduced in human subjects with asthma, which suggests that CD163 may participate in the regulation of airway inflammatory responses in the lung (85). In addition, sCD163 is inversely associated with predicted forced expiratory volume in $1 \mathrm{sec}$ in patients with asthma (9) and COPD, particularly in those with severe disease (94). During Dermatophagoides pteronyssinus (Dp)-induced bronchoconstriction, alterations in monocyte CD163 expression and sCD163 were negatively correlated with fractional exhaled nitric oxide concentrations (99). Asthma in obese adults has been associated with impaired macrophage efferocytosis. This impairment is associated with altered monocyte programming, impaired response to glucocorticoids and systemic oxidative stress (62). Obese asthmatic children exhibit increased sCD163 expression, in addition to sex-specific macrophage activation, which may impair asthma control and lung function (9). Furthermore, sCD163 concentration in sputum is significantly higher in patients with allergic asthma compared with in controls. Treatment with inhaled corticosteroids results in a significant increase in sCD163 concentrations in sputum (33). Macrophages isolated from sputum samples from patients with asthma demonstrate significantly higher CCL17 and lower CD163 mRNA expression levels compared with macrophages from healthy subjects (100). CD163+ alveolar macrophages were decreased in patients with asthma (85), whereas sputum sCD163 levels were increased (33). This inverse relationship between surface and soluble CD163 has already been described (44). Therefore, we speculate that airway inflammation and some inflammatory mediators induce alveolar macrophages to release CD163 from the cell surface in patients with asthma, and sCD163 participates in the airway inflammatory response, and the phagocytosis of $\mathrm{CD}_{163}{ }^{+} \mathrm{M} 2$ macrophages is impaired in asthma.

\section{Conclusion}

Macrophages serve a key role in the regulation of immunity and tissue remodeling. CD163, which is a transmembrane scavenger receptor found on the surface of macrophages, is released in the circulation in its soluble form, sCD163, via cleavage by MMPs following oxidative stress or inflammatory stimuli. sCD163 is involved in the pathogenesis of autoimmune diseases, atherosclerosis, diabetes and cancer. Bronchial asthma is characterized by nonspecific inflammation of the airways, and the alternatively activated $\mathrm{CD}_{163}{ }^{+} \mathrm{M} 2$ macrophages have a key role in this pathological condition. Through phagocytosis and the subsequent release of biologically active substances, neutrophils participate in defense mechanisms of the airways. After completing their mission, neutrophils undergo apoptosis. 
Macrophages effectively eliminate apoptotic neutrophils, a process critical in suppressing acute inflammation and restoring homeostasis. Neutrophil elastase has been revealed to enhance CD163 shedding, and sCD163 is a marker of macrophage activation. Neutrophil elastase serves as a neutrophil activation marker, which suggests that macrophage activation is associated with the activation of neutrophils. A Th1/Th2 imbalance has been suggested as an indicator of the pathogenesis of asthma. Th2 cytokines, such as IL-4, IL-13 and IL-10, can influence M2 macrophage activation. IL-10 and IL-6 promote sCD163 shedding from M2 macrophages, whereas release of Th17 and IL-17 can inhibit the apoptosis of $\mathrm{CD} 63^{+} \mathrm{M} 2$ macrophages. In addition, M2 macrophages are associated with $\mathrm{T}$ lymphocytes. IL-4 and IL-13 can stimulate eosinophil activation. sCD163, a marker of M2 macrophages, is associated with the eosinophil count through several cytokines. Furthermore, sCD163 is associated with body mass index in patients with asthma, and the concentration of sCD163 in plasma or induced sputum is inversely correlated to predicted forced expiratory volume in $1 \mathrm{sec}$. Therefore, investigating the role of sCD163 may contribute to elucidating the underlying molecular mechanisms of asthma, and may represent a promising target for the development of effective therapeutic agents for the treatment of asthma.

\section{References}

1. Becker M, De Bastiani MA, Parisi MM, Guma FT, Markoski MM, Castro MA, Kaplan MH, Barbé-Tuana FM and Klamt F: Integrated transcriptomics establish macrophage polarization signatures and have potential applications for clinical health and disease. Sci Rep 5: 13351, 2015.

2. Vishwanath P, Prashant A, Nataraj SM, Kotekar N and Doddamani P: Can soluble CD163 predict outcome of patients with acute respiratory distress from mechanical ventilation? A pilot study. Indian J Crit Care Med 17: 355-358, 2013.

3. Buechler C, Eisinger K and Krautbauer S: Diagnostic and prognostic potential of the macrophage specific receptor CD163 in inflammatory diseases. Inflamm Allergy Drug Targets 12: 391-402, 2013.

4. Bielecki M, Kowal K, Lapinska A, Chyczewski L and Kowal-Bielecka O: Increased release of soluble CD163 by the peripheral blood mononuclear cells is associated with worse prognosis in patients with systemic sclerosis. Adv Med Sci 58: 126-133, 2013.

5. Thomsen HH, Møller HJ, Trolle C, Groth KA, Skakkebæk A, Bojesen A, Høst C and Gravholt CH: The macrophage low-grade inflammation marker sCD163 is modulated by exogenous sex steroids. Endocr Connect 2: 216-224, 2013.

6. Shimizu K, Ogawa F, Yoshizaki A, Akiyama Y, Kuwatsuka Y, Okazaki S, Tomita H, Takenaka $\mathrm{M}$ and Sato S: Increased serum levels of soluble CD163 in patients with scleroderma. Clin Rheumatol 31: 1059-1064, 2012.

7. Fabriek BO, Møller HJ, Vloet RP, van Winsen LM, Hanemaaijer R, Teunissen CE, Uitdehaag BM, van den Berg TK and Dijkstra CD: Proteolytic shedding of the macrophage scavenger receptor CD163 in multiple sclerosis. J Neuroimmunol 187: 179-186, 2007.

8. Timmermann $\mathrm{M}$ and Högger P: Oxidative stress and 8-iso-prostaglandin F (2alpha) induce ectodomain shedding of CD163 and release of tumor necrosis factor-alpha from human monocytes. Free Radic Biol Med 39: 98-107, 2005.

9. Periyalil HA, Wood LG, Scott HA, Jensen ME and Gibson PG: Macrophage activation, age and sex effects of immunometabolism in obese asthma. Eur Respir J 45: 388-395, 2015.

10. Davis BH and Zarev PV: Human monocyte CD163 expression inversely correlates with soluble CD163 plasma levels. Cytometry B Clin Cytom 63: 16-22, 2005.

11. Etzerodt A, Maniecki MB, Møller K, Møller HJ and Moestrup SK: Tumor necrosis factor $\alpha$-converting enzyme (TACE/ADAM17) mediates ectodomain shedding of the scavenger receptor CD163. J Leukoc Biol 88: 1201-1205, 2010.
12. Møller HJ, Aerts H, Grønbaek H, Peterslund NA Hyltoft Petersen P, Hornung N, Rejnmark L, Jabbarpour E and Moestrup SK: Soluble CD163: A marker molecule for monocyte/macrophage activity in disease. Scand J Clin Lab Invest Suppl 237: 29-33, 2002.

13. Verreck FA, de Boer T, Langenberg DM, van der Zanden L and Ottenhoff TH: Phenotypic and functional profiling of human proinflammatory type- 1 and anti-inflammatory type- 2 macrophages in response to microbial antigens and IFN-gamma- and CD40L-mediated costimulation. J Leukoc Biol 79: 285-293, 2006.

14. Savage ND, de Boer T, Walburg KV, Joosten SA, van Meijgaarden K, Geluk A and Ottenhoff TH: Human anti-inflammatory macrophages induce Foxp $3^{+} \mathrm{GITR}^{+} \mathrm{CD} 25^{+}$ regulatory $\mathrm{T}$ cells, which suppress via membrane-bound TGFbeta-1. J Immunol 181: 2220-2226, 2008.

15. Xu W, Roos A, Schlagwein N, Woltman AM, Daha MR and van Kooten C: IL-10-producing macrophages preferentially clear early apoptotic cells. Blood 107: 4930-4937, 2006.

16. Schmieder A, Schledzewski K, Michel J, Schönhaar K, Morias Y, Bosschaerts T, Van den Bossche J, Dorny P, Sauer A, Sticht C, et al: The CD20 homolog Ms4a8a integrates pro- and anti-inflammatory signals in novel M2-like macrophages and is expressed in parasite infection. Eur J Immunol 42: 2971-2982, 2012

17. Paulus P, Holfeld J, Urbschat A, Mutlak H, Ockelmann PA, Tacke S, Zacharowski K, Reissig C, Stay D and Scheller B: Prednisolone as preservation additive prevents from ischemia reperfusion injury in a rat model of orthotopic lung transplantation. PLoS One 8: e73298, 2013

18. Duvel A, Frank C, Schnapper A, Schuberth HJ and Sipka A: Classically or alternatively activated bovine monocyte-derived macrophages in vitro do not resemble CD163/Calprotectin biased macrophage populations in the teat. Innate Immun 18: 886-896, 2012.

19. Zizzo G and Cohen PL: IL-17 stimulates differentiation of human anti-inflammatory macrophages and phagocytosis of apoptotic neutrophils in response to IL-10 and glucocorticoids. J Immunol 190: 5237-5246, 2013.

20. Fujimura T, Kambayashi Y, Furudate S, Kakizaki A and Aiba S: A possible mechanism in the recruitment of eosinophils and Th2 cells through CD163(+) M2 macrophages in the lesional skin of eosinophilic cellulitis. Eur J Dermatol 24: 180-185, 2014.

21. Onofre G, Koláčková M, Jankovičová K and Krejsek J: Scavenger receptor CD163 and its biological functions. Acta Medica (Hradec Kralove) 52: 57-61, 2009.

22. Sulahian TH, Pioli PA, Wardwell K and Guyre PM: Cross-linking of FcgammaR triggers shedding of the hemoglobin-haptoglobin scavenger receptor CD163. J Leukoc Biol 76: 271-277, 2004.

23. Kneidl J, Loffler B, Erat MC, Kalinka J, Peters G, Roth J and Barczyk K: Soluble CD163 promotes recognition, phagocytosis and killing of Staphylococcus aureus via binding of specific fibronectin peptides. Cell Microbiol 14: 914-936, 2012.

24. Knudsen TB, Gustafson P, Kronborg G, Kristiansen TB Moestrup SK, Nielsen JO, Gomes V, Aaby P, Lisse I, Møller HJ and Eugen-Olsen J: Predictive value of soluble haemoglobin scavenger receptor CD163 serum levels for survival in verified tuberculosis patients. Clin Microbiol Infect 11: 730-735, 2005.

25. Madsen M, Møller HJ, Nielsen MJ, Jacobsen C, Graversen JH, van den Berg T and Moestrup SK: Molecular characterization of the haptoglobin.hemoglobin receptor CD163. Ligand binding properties of the scavenger receptor cysteine-rich domain region. J Biol Chem 279: 51561-51567, 2004.

26. Maniecki MB, Etzerodt A, Moestrup SK, Møller HJ and Graversen JH: Comparative assessment of the recognition of domain-specific CD163 monoclonal antibodies in human monocytes explains wide discrepancy in reported levels of cellular surface CD163 expression. Immunobiology 216: 882-890, 2011.

27. Etzerodt A, Rasmussen MR, Svendsen P, Chalaris A, Schwarz J, Galea I, Møller HJ and Moestrup SK: Structural basis for inflammation-driven shedding of CD163 ectodomain and tumor necrosis factor- $\alpha$ in macrophages. J Biol Chem 289: 778-788, 2014.

28. Subramanian K, Du R, Tan NS, Ho B and Ding JL: CD163 and IgG codefend against cytotoxic hemoglobin via autocrine and paracrine mechanisms. J Immunol 190: 5267-5278, 2013.

29. Møller HJ, Nielsen MJ, Maniecki MB, Madsen M and Moestrup SK: Soluble macrophage-derived CD163: A homogenous ectodomain protein with a dissociable haptoglobin-hemoglobin binding. Immunobiology 215: 406-412, 2010. 
30. Craig DG, Lee P, Pryde EA, Hayes PC and Simpson KJ: Serum neopterin and soluble CD163 as markers of macrophage activation in paracetamol (acetaminophen)-induced human acute liver injury. Aliment Pharmacol Ther 38: 1395-1404, 2013.

31. Hintz KA, Rassias AJ, Wardwell K, Moss ML, Morganelli PM, Pioli PA, Givan AL, Wallace PK, Yeager MP and Guyre PM: Endotoxin induces rapid metalloproteinase-mediated shedding followed by up-regulation of the monocyte hemoglobin scavenger receptor CD163. J Leukoc Biol 72: 711-717, 2002.

32. Salagianni M, Galani IE, Lundberg AM, Davos $\mathrm{CH}$ Varela A, Gavriil A, Lyytikäinen LP, Lehtimäki T, Sigala F, Folkersen L, et al: Toll-like receptor 7 protects from atherosclerosis by constraining 'inflammatory' macrophage activation. Circulation 126: 952-962, 2012.

33. Kowal K, Moniuszko M and Bodzenta-Lukaszyk A: The effect of inhaled corticosteroids on the concentration of soluble CD163 in induced sputum of allergic asthma patients. J Investig Allergol Clin Immunol 24: 49-55, 2014.

34. Goldstein JI, Goldstein KA, Wardwell K, Fahrner SL, Goonan KE, Cheney MD, Yeager MP and Guyre PM: Increase in plasma and surface CD163 levels in patients undergoing coronary artery bypass graft surgery. Atherosclerosis 170: 325-332, 2003.

35. Hogger P and Sorg C: Soluble CD163 inhibits phorbol ester-induced lymphocyte proliferation. Biochem Biophys Res Commun 288: 841-843, 2001.

36. Funding M, Vorum H, Nexø E, Moestrup SK, Ehlers N and Møller HJ: Soluble CD163 and interleukin-6 are increased in aqueous humour from patients with endothelial rejection of corneal grafts. Acta Ophthalmol Scand 83: 234-239, 2005

37. Jude C, Dejica D, Samasca G, Balacescu L and Balacescu O Soluble CD163 serum levels are elevated and correlated with IL-12 and CXCL10 in patients with long-standing rheumatoid arthritis. Rheumatol Int 33: 1031-1037, 2013.

38. Kneidl J, Mysore V, Geraci J, Tuchscherr L, Löffler B Holzinger D, Roth J and Barczyk-Kahlert K: Soluble CD163 masks fibronectin-binding protein A-mediated inflammatory activation of Staphylococcus aureus infected monocytes. Cell Microbiol 16: 364-377, 2014.

39. Kusi KA, Gyan BA, Goka BQ, Dodoo D, Obeng-Adjei G, Troye-Blomberg M, Akanmori BD and Adjimani JP: Levels of soluble CD163 and severity of malaria in children in Ghana. Clin Vaccine Immunol 15: 1456-1460, 2008.

40. Andersen ES, Rødgaard-Hansen S, Moessner B, Christensen PB, Møller HJ and Weis N: Macrophage-related serum biomarkers soluble CD163 (sCD163) and soluble mannose receptor (sMR) to differentiate mild liver fibrosis from cirrhosis in patients with chronic hepatitis C: A pilot study. Eur J Clin Microbiol Infect Dis 33: 117-122, 2014

41. Gaini S, Pedersen SS, Koldkaer OG, Pedersen C, Moestrup SK and Møller HJ: New immunological serum markers in bacteraemia: Anti-inflammatory soluble CD163, but not proinflammatory high mobility group-box 1 protein, is related to prognosis. Clin Exp Immunol 151: 423-431, 2008.

42. Ayarci AO, Yilmaz E, Sigirli D, Budak F, Göral G and Oral HB Diagnostic value of serum concentrations of high-mobility group-box protein 1 and soluble hemoglobin scavenger receptor in brucellosis. Microbiol Immunol 57: 150-158, 2013.

43. Knudsen TB, Larsen K, Kristiansen TB, Møller HJ, Tvede M, Eugen-Olsen J and Kronborg G: Diagnostic value of soluble CD163 serum levels in patients suspected of meningitis: Comparison with CRP and procalcitonin. Scand J Infect Dis 39: 542-553, 2007.

44. Costa-Hurtado M, Olvera A, Martinez-Moliner V, Galofré-Milà N, Martínez $\mathrm{P}$, Dominguez $\mathrm{J}$ and Aragon V: Changes in macrophage phenotype after infection of pigs with Haemophilus parasuis strains with different levels of virulence. Infect Immun 81: 2327-2333, 2013.

45. Carrol ED, Mankhambo LA, Jeffers G, Parker D, Guiver M, Newland P and Banda DL; IPD Study Group, Molyneux EM, Heyderman RS: The diagnostic and prognostic accuracy of five markers of serious bacterial infection in Malawian children with signs of severe infection. PLoS One 4: e6621, 2009.

46. Cui Y, Zhang YC, Rong QF and Zhu Y: Changes and significance of soluble CD163 in sepsis and severe sepsis in children. Zhonghua Er Ke Za Zhi 50: 653-656, 2012 (In Chinese).

47. Su L, Feng L, Liu C, Jiang Z, Li M, Xiao K, Yan P, Jia Y, Feng D and Xie L: Diagnostic value of urine sCD163 levels for sepsis and relevant acute kidney injury: A prospective study. BMC Nephrol 13: 123, 2012.
48. Kjaergaard AG, Rodgaard-Hansen S, Dige A, Krog J, Møller HJ and Tønnesen E: Monocyte expression and soluble levels of the haemoglobin receptor (CD163/sCD163) and the mannose receptor (MR/sMR) in septic and critically ill non-septic ICU patients. PLoS One 9: e92331, 2014.

49. Gronbaek H, Sandahl TD, Mortensen C, Vilstrup H, Møller HJ and Møller S: Soluble CD163, a marker of Kupffer cell activation, is related to portal hypertension in patients with liver cirrhosis. Aliment Pharmacol Ther 36: 173-180, 2012.

50. Yang YY, Huang YT, Tsai TH, Hou MC, Lee FY, Lee SD and Lin HC: Kupffer cell depletion attenuates leptin-mediated methoxamine-stimulated portal perfusion pressure and thromboxane A2 release in a rodent model of NASH-cirrhosis. Clin Sci (Lond) 123: 669-680, 2012.

51. Bover LC, Cardo-Vila M, Kuniyasu A, Sun J, Rangel R, Takeya M, Aggarwal BB, Arap W and Pasqualini R: A previously unrecognized protein-protein interaction between TWEAK and CD163: Potential biological implications. J Immunol 178: 8183-8194, 2007.

52. Waidmann O, Brunner F, Herrmann E, Zeuzem S, Piiper A and Kronenberger B: Macrophage activation is a prognostic parameter for variceal bleeding and overall survival in patients with liver cirrhosis. J Hepatol 58: 956-961, 2013.

53. Yang YY, Hou MC, Lin MW, Chen PH, Liao WC, Chu CJ and Lin HC: Combined platelet count with sCD163 and genetic variants optimizes esophageal varices prediction in cirrhotic patients. J Gastroenterol Hepatol 28: 112-121, 2013.

54. Kazankov K, Barrera F, Møller HJ, Bibby BM, Vilstrup H, George J and Grønbaek H: Soluble CD163, a macrophage activation marker, is independently associated with fibrosis in patients with chronic viral hepatitis B and C. Hepatology 60: 521-530, 2014

55. Ye H, Wang LY, Zhao J and Wang K: Increased CD163 expression is associated with acute-on-chronic hepatitis B liver failure. World J Gastroenterol 19: 2818-2825, 2013.

56. Møller HJ, Grønbaek H, Schiødt FV, Holland-Fischer P, Schilsky M, Munoz S, Hassanein T and Lee WM; U.S. Acute Liver Failure Study Group: Soluble CD163 from activated macrophages predicts mortality in acute liver failure. J Hepatol 47: 671-676, 2007.

57. Parkner T, Sorensen LP, Nielsen AR, Fischer CP, Bibby BM, Nielsen S, Pedersen BK and Møller HJ: Soluble CD163: A biomarker linking macrophages and insulin resistance. Diabetologia 55: 1856-1862, 2012.

58.Zanni MV, Burdo TH, Makimura H, Williams KC and Grinspoon SK: Relationship between monocyte/macrophage activation marker soluble CD163 and insulin resistance in obese and normal-weight subjects. Clin Endocrinol (Oxf) 77: 385-390, 2012.

59. Diaz-López A, Chacón MR, Bulló M, Maymó-Masip E, Martínez-González MA, Estruch R, Vendrell J, Basora J, Díez-Espino J, Covas MI and Salas-Salvadó J: Serum sTWEAK concentrations and risk of developing type 2 diabetes in a high cardiovascular risk population: A nested case-control study. J Clin Endocrinol Metab 98: 3482-3490, 2013.

60. Møller HJ, Frikke-Schmidt R , Moestrup SK, Nordestgaard BG and Tybjaerg-Hansen A: Serum soluble CD163 predicts risk of type 2 diabetes in the general population. Clin Chem 57: 291-297, 2011

61. Llauradó G, González-Clemente JM, Maymó-Masip E, Subías D, Vendrell J and Chacón MR: Serum levels of TWEAK and scavenger receptor CD163 in type 1 diabetes mellitus: Relationship with cardiovascular risk factors. A case-control study. PLoS One 7: e43919, 2012.

62. Fernandez-Boyanapalli R, Goleva E, Kolakowski C, Min E, Day B, Leung DY, Riches DW, Bratton DL and Sutherland ER: Obesity impairs apoptotic cell clearance in asthma. J Allergy Clin Immunol 131: 1041-1047, 1047.e1-e3, 2013.

63. Shakeri-Manesch S, Zeyda M, Huber J, Ludvik B, Prager G and Stulnig TM: Diminished upregulation of visceral adipose heme oxygenase-1 correlates with waist-to-hip ratio and insulin resistance. Int J Obes (Lond) 33: 1257-1264, 2009.

64. Al-Daghri NM, Al-Attas OS, Bindahman LS, Alokail MS Alkharfy KM, Draz HM, Yakout S, McTernan PG, Sabico S and Chrousos GP: Soluble CD163 is associated with body mass index and blood pressure in hypertensive obese Saudi patients. Eur J Clin Invest 42: 1221-1226, 2012.

65. Kračmerová J, Rossmeislová L, Kováčová Z, Klimčáková E, Polák J, Tencerová M, Mališová L, Štich V, Langin D and Šiklová M: Soluble CD163 is associated with CD163 mRNA expression in adipose tissue and with insulin sensitivity in steady-state condition but not in response to calorie restriction. J Clin Endocrinol Metab 99: E528-E535, 2014. 
66. Fjeldborg K, Christiansen T, Bennetzen M, J Møller $\mathrm{H}$, Pedersen SB and Richelsen B: The macrophage-specific serum marker, soluble CD163, is increased in obesity and reduced after dietary-induced weight loss. Obesity (Silver Spring) 21: 2437-2443, 2013.

67. Longenecker CT, Jiang Y, Yun CH, Debanne S, Funderburg NT, Lederman MM, Storer N, Labbato DE, Bezerra HG and McComsey GA: Perivascular fat, inflammation, and cardiovascular risk in HIV-infected patients on antiretroviral therapy. Int J Cardiol 168: 4039-4045, 2013.

68. Knudsen A, Møller HJ, Katzenstein TL, Gerstoft J, Obel N, Kronborg G, Benfield T, Kjaer A and Lebech AM: Soluble CD163 does not predict first-time myocardial infarction in patients infected with human immunodeficiency virus: A nested case-control study. BMC Infect Dis 13: 230, 2013.

69. Levy AP, Purushothaman KR, Levy NS, Purushothaman M, Strauss M, Asleh R, Marsh S, Cohen O, Moestrup SK, Moller HJ, et al: Downregulation of the hemoglobin scavenger receptor in individuals with diabetes and the Hp 2-2 genotype: Implications for the response to intraplaque hemorrhage and plaque vulnerability. Circ Res 101: 106-110, 2007.

70. Kowal-Bielecka O, Bielecki M, Guiducci S, Trzcinska-Butkiewicz B, Michalska-Jakubus M, Matucci-Cerinic M, Brzosko M, Krasowska D, Chyczewski L and Kowal K: High serum sCD163/sTWEAK ratio is associated with lower risk of digital ulcers but more severe skin disease in patients with systemic sclerosis. Arthritis Res Ther 15: R69, 2013.

71. Shaked I, Hanna DB, Gleißner C, Marsh B, Plants J, Tracy D, Anastos K, Cohen M, Golub ET, Karim R, et al: Macrophage inflammatory markers are associated with subclinical carotid artery disease in women with human immunodeficiency virus or hepatitis $\mathrm{C}$ virus infection. Arterioscler Thromb Vasc Biol 34 1085-1092, 2014

72. Urbonaviciene G, Martin-Ventura JL, Lindholt JS Urbonavicius S, Moreno JA, Egido J and Blanco-Colio LM: Impact of soluble TWEAK and CD163/TWEAK ratio on long-term cardiovascular mortality in patients with peripheral arterial disease. Atherosclerosis 219: 892-899, 2011.

73. Moreno JA, Dejouvencel T, Labreuche J, Smadja DM, Dussiot M, Martin-Ventura JL, Egido J, Gaussem P, Emmerich J, Michel JB, et al: Peripheral artery disease is associated with a high CD163/TWEAK plasma ratio. Arterioscler Thromb Vasc Biol 30: 1253-1262, 2010.

74. Moreno JA, Ortega-Gómez A, Delbosc S, Beaufort N, Sorbets E, Louedec L, Esposito-Farèse $M$, Tubach $F$, Nicoletti $A$, Steg PG, et al: In vitro and in vivo evidence for the role of elastase shedding of CD163 in human atherothrombosis. Eur Heart J 33: 252-263, 2012.

75. Nakayama W, Jinnin M, Makino K, Kajihara I, Makino T, Fukushima S, Inoue Y and Ihn H: Serum levels of soluble CD163 in patients with systemic sclerosis. Rheumatol Int 32: 403-407, 2012.

76. Greisen SR, Møller HJ, Stengaard-Pedersen K, Hetland ML, Hørslev-Petersen K, Jørgensen A, Hvid M and Deleuran B: Soluble macrophage-derived CD163 is a marker of disease activity and progression in early rheumatoid arthritis. Clin Exp Rheumatol 29: 689-692,2011.

77. De Rycke L, Baeten D, Foell D, Kruithof E, Veys EM, Roth J and De Keyser F: Differential expression and response to anti-TNFalpha treatment of infiltrating versus resident tissue macrophage subsets in autoimmune arthritis. J Pathol 206: $17-27,2005$

78. Zizzo G, Guerrieri J, Dittman LM, Merri JT and Cohen PL: Circulating levels of soluble MER in lupus reflect M2c activation of monocytes/macrophages, autoantibody specificities and disease activity. Arthritis Res Ther 15: R212, 2013.

79. Nakayama W, Jinnin M, Makino K, Kajihara I, Makino T, Fukushima S, Sakai K, Inoue Y and Ihn H: CD163 expression is increased in the involved skin and sera of patients with systemic lupus erythematosus. Eur J Dermatol 22: 512-517, 2012.

80. Waidmann O, Köberle V, Bettinger D, Trojan J, Zeuzem S, Schultheiß M, Kronenberger B and Piiper A: Diagnostic and prognostic significance of cell death and macrophage activation markers in patients with hepatocellular carcinoma. J Hepatol 59: 769-779, 2013.

81. Lim R, Lappas M, Riley C, Borregaard N, Moller HJ, Ahmed N and Rice GE: Investigation of human cationic antimicrobial protein-18 (hCAP-18), lactoferrin and CD163 as potential biomarkers for ovarian cancer. J Ovarian Res 6: 5, 2013
82. No JH, Moon JM, Kim K and Kim YB: Prognostic significance of serum soluble CD163 level in patients with epithelial ovarian cancer. Gynecol Obstet Invest 75: 263-267, 2013.

83. Sugaya M, Miyagaki T, Ohmatsu H, Suga H, Kai H, Kamata M, Fujita H, Asano Y, Tada Y, Kadono T, et al: Association of the numbers of CD163(+) cells in lesional skin and serum levels of soluble CD163 with disease progression of cutaneous T cell lymphoma. J Dermatol Sci 68: 45-51, 2012.

84. Andersen MN, Abildgaard N, Maniecki MB, Møller HJ and Andersen NF: Monocyte/macrophage-derived soluble CD163: A novel biomarker in multiple myeloma. Eur J Haematol 93: 41-47, 2014

85. Dai C, Yao X, Gordon EM, Barochia A, Cuento RA, Kaler M, Meyer KS, Keeran KJ, Nugent GZ, Jeffries KR, et al: A CCL24-dependent pathway augments eosinophilic airway inflammation in house dust mite-challenged Cd163 mice. Mucosal Immunol 9: 702-717, 2016

86. Akahori H, Karmali V, Polavarapu R, Lyle AN, Weiss D, Shin E, Husain A, Naqvi N, Van Dam R, Habib A, et al: CD163 interacts with TWEAK to regulate tissue regeneration after ischaemic injury. Nat Commun 6: 7792, 2015.

87. Etzerodt A, Kjolby M, Nielsen MJ, Maniecki M, Svendsen P and Moestrup SK: Plasma clearance of hemoglobin and haptoglobin in mice and effect of CD163 gene targeting disruption. Antioxid Redox Signal 18: 2254-2263, 2013.

88. Draijer C, Robbe P, Boorsma CE, Hylkema MN and Melgert BN: Characterization of macrophage phenotypes in three murine models of house-dust-mite-induced asthma. Mediators Inflamm 2013: 632049, 2013.

89. Liu YC, Zou XB, Chai YF and Yao YM: Macrophage polarization in inflammatory diseases. Int J Biol Sci 10: 520-529, 2014.

90. Byrne AJ, Mathie SA, Gregory LG and Lloyd CM: Pulmonary macrophages: Key players in the innate defence of the airways. Thorax 70: 1189-1196, 2015.

91. Kunz LI, Lapperre TS, Snoeck-Stroband JB, Budulac SE Timens W, van Wijngaarden S, Schrumpf JA, Rabe KF, Postma DS, Sterk PJ, et al: Smoking status and anti-inflammatory macrophages in bronchoalveolar lavage and induced sputum in COPD. Respir Res 12: 34, 2011.

92. Zhang X, Zhong W, Meng Q, Lin Q, Fang C, Huang X, Li C, Huang Y and Tan J: Ambient PM2.5 exposure exacerbates severity of allergic asthma in previously sensitized mice. J Asthma 52: 785-794, 2015.

93. Martinez-Nunez RT, Louafi F and Sanchez-Elsner T: The interleukin 13 (IL-13) pathway in human macrophages is modulated by microRNA-155 via direct targeting of interleukin 13 receptor alpha1 (IL13Ralpha1). J Biol Chem 286: 1786-1794, 2011.

94. Moreira AP, Cavassani KA, Hullinger R, Rosada RS, Fong DJ, Murray L, Hesson DP and Hogaboam CM: Serum amyloid P attenuates M2 macrophage activation and protects against fungal spore-induced allergic airway disease. J Allergy Clin Immunol 126: 712-721.e7, 2010.

95. Han H,Headley MB, Xu W, Comeau MR, Zhou B and Ziegler SF: Thymic stromal lymphopoietin amplifies the differentiation of alternatively activated macrophages. J Immunol 190: 904-912, 2013.

96. Hamzaoui A, Ammar J and Hamzaoui K: Regulatory T cells in induced sputum of asthmatic children: Association with inflammatory cytokines. Multidiscip Respir Med 5: 22-30, 2010.

97. Siddiqui S, Secor ER Jr and Silbart LK: Broncho-alveolar macrophages express chemokines associated with leukocyte migration in a mouse model of asthma. Cell Immunol 281: $159-169,2013$

98. Abdullah M, Kahler D, Vock C, Reiling N, Kugler C, Drömann D, Rupp J, Hauber HP, Fehrenbach H, Zabel P, et al: Pulmonary haptoglobin and CD163 are functional immunoregulatory elements in the human lung. Respiration 83: 61-73, 2012.

99. Axelsson J, Møller HJ, Witasp A, Qureshi AR, Carrero JJ, Heimbürger O, Bárány P, Alvestrand A, Lindholm B, Moestrup SK and Stenvinkel P: Changes in fat mass correlate with changes in soluble sCD163, a marker of mature macrophages, in patients with CKD. Am J Kidney Dis 48: 916-925, 2006.

100. Staples KJ, Hinks TS, Ward JA, Gunn V, Smith C and Djukanović R: Phenotypic characterization of lung macrophages in asthmatic patients: Overexpression of CCL17. J Allergy Clin Immunol 130: 1404-1412.e7, 2012. 